\title{
Ultrasound evidence of the optimal wrist position for radial artery cannulation
}

\section{Positionnement optimal du poignet par échoguidage lors de la canulation de l'artère radiale}

\author{
Keiko Mizukoshi, MD - Masayuki Shibasaki, MD - Fumimasa Amaya, MD · \\ Takahiro Hirayama, MD · Fumihiro Shimizu, MD · Koji Hosokawa, MD • \\ Satoru Hashimoto, MD · Yoshifumi Tanaka, MD
}

Received: 18 September 2008/Revised: 9 March 2009/Accepted: 12 March 2009/Published online: 25 April 2009

(C) Canadian Anesthesiologists' Society 2009

\begin{abstract}
Purpose Radial artery cannulation is a common medical procedure for anesthesia and critical care. To establish the ideal wrist position for radial artery cannulation, we performed ultrasound examinations of the radial artery to investigate the effect of the angle of wrist extension on radial artery dimensions.

Clinical features Measurements were performed in 17 healthy subjects and 17 surgical patients scheduled for coronary artery bypass graft (CABG) surgery. The radial artery was echographically visualized near the styloid process of the radius at the wrist. Radial artery dimensions were measured at wrist joint angles of 0, 15, 30, 45, 60 and $75^{\circ}$.

Observations In both groups, radial artery height was affected by the wrist joint angle. Vessel height was decreased at $60^{\circ}$ (one way ANOVA $P=0.027$ vs $0^{\circ}$ ) and $75^{\circ}\left(P<0.001\right.$ vs $\left.0,15,45^{\circ}\right)$ in healthy subject and at $75^{\circ}$ in $C A B G$ patients $\left(P<0.001\right.$ vs $\left.0^{\circ}\right)$. The mean differences in radial artery height at 0 and $75^{\circ}$ were $0.33 \pm 0.09 \mathrm{~mm}$ and $0.20 \pm 0.06 \mathrm{~mm}$ for healthy and CABG patients, respectively. Vessel width was not affected by wrist joint angulation up to $75^{\circ}$ of extension.
\end{abstract}

K. Mizukoshi, MD - M. Shibasaki, MD - F. Amaya, MD ( $)$.

T. Hirayama, MD · F. Shimizu, MD - K. Hosokawa, MD

S. Hashimoto, MD · Y. Tanaka, MD

Department of Anesthesiology and Intensive Care Medicine,

Kyoto Prefectural University of Medicine, 465 Kajiicho,

Kamigyo-ku, Kyoto 602-8566, Japan

e-mail: ama@koto.kpu-m.ac.jp
Conclusion Our results demonstrate that in healthy subjects, radial artery dimensions are unaltered when the wrist joint is extended up to an angle of $45^{\circ}$. Extension at $60^{\circ}$ for healthy subjects and $75^{\circ}$ for CABG patients, however, results in a decrease in the height of the radial artery, which could possibly render arterial catheterization more difficult.

\section{Résumé}

Objectif La canulation de l'artère radiale est un geste médical courant en anesthésie et aux soins intensifs. Afin de déterminer la position optimale du poignet pour canuler de l'artère radiale, nous avons réalisé des examens échographiques de l'artère radiale pour examiner l'effet de l'angle d'extension $d u$ poignet sur les dimensions de l'artère radiale.

Éléments cliniques Les mesures ont été réalisées chez 17 patients sains et 17 patients devant subir des pontages aortocoronariens (PAC). L'artère radiale a été visualisée par échographie au niveau du poignet, près de l'apophyse styloïle du radius. Les dimensions de l'artère radiale ont été mesurées à des angles du poignet de $0^{\circ}, 15^{\circ}, 30^{\circ}, 45^{\circ}$, $60^{\circ}$ et $75^{\circ}$.

Observations La hauteur de l'artère radiale a été affectée par l'angle du poignet dans les deux groupes. La hauteur des vaisseaux était réduite à un angle de $60^{\circ}$ (ANOVA simple $P=0,027$ versus $\left.0^{\circ}\right)$ et $75^{\circ}(P<0,001$ versus $\left.0^{\circ}, 15^{\circ}, 45^{\circ}\right)$ chez les patients sains et à $75^{\circ}$ chez les patients subissant un PAC $\left(P<0,001\right.$ versus $\left.0^{\circ}\right)$. Les différences moyennes des hauteurs de l'artère radiale à $0^{\circ}$ et $75^{\circ}$ étaient de 0,33 $\pm 0,09 \mathrm{~mm}$ et 0,20 $\pm 0,06 \mathrm{~mm}$ chez les patients sains et les patients subissant un PAC, respectivement. La largeur des vaisseaux n'a pas été affectée par l'angulation du poignet jusqu'à $75^{\circ}$ d'extension. 
Conclusion Nos résultats démontrent que chez les patients sains, les dimensions de l'artère radiale ne changent pas lorsque l'articulation du poignet est étendue jusqu'à un angle de $45^{\circ}$. Une extension à $60^{\circ}$ chez les patients sains et à $75^{\circ}$ chez les patients subissant un PAC a toutefois pour résultat une réduction de la hauteur de l'artère radiale, ce qui pourrait possiblement rendre la canulation artérielle plus difficile.

Arterial cannulation is a common technique for continuous hemodynamic monitoring in anesthesia and intensive care settings. The distal part of the radial artery at the wrist is the most frequently used site for arterial cannulation because of the relatively low incidence of complications and the ease of access to this site during anesthesia. ${ }^{1}$ More than two arterial punctures are required in $15-27 \%$ of patients undergoing general anesthesia before successful catheter insertion into the radial artery can be established. ${ }^{2,3}$ Radial artery cannulation failure occurs in 1-5\% of patients undergoing percutaneous coronary angioplasty, ${ }^{4}$ which is a higher failure rate than for brachial or femoral artery cannulation. ${ }^{5}$ The high failure rate of radial artery puncture may be due to the small arterial size at the wrist in adults (ranging from 1.5 to $3.5 \mathrm{~mm}^{6,7}$ ) relative to the size of the needle commonly used for arterial puncture (the outer diameter of a $20-\mathrm{G}$ Teflon needle is $1.0 \mathrm{~mm}$ ).

Many medical textbooks provide a detailed description of the procedure for radial artery catheterization and recommend that the wrist joint be kept in a mildly extended position. Overextension should be avoided, since it attenuates radial arterial pulsations at the wrist joint ${ }^{8}$; however, there is no established consensus for the optimal angle positioning of the wrist joint during radial artery cannulation. In previous clinical trials, wrist joints were differentially fixed at angles varying from $45^{\circ 9}$ to $70^{\circ 10}$ during catheter insertion.

To establish appropriate wrist joint position for arterial cannulation, we used ultrasound echography to investigate the effect of wrist joint position on radial artery diameter in healthy subjects and in patients undergoing coronary artery bypass grafting (CABG).

\section{Methods}

Seventeen healthy adults (nine men and eight women, 22 to 38 years of age; mean age $=28.6$ years) and 17 surgical patients scheduled for coronary artery bypass grafting (CABG) (12 men and five women, 50 to 80 years of age; mean age $=68.6$ years) were involved in this study. The institutional review board of Kyoto Prefectural University of Medicine approved the study, and informed consent was obtained from all participants. Patients with a history of peripheral vascular disease were excluded. Patients scheduled for CABG surgery underwent ultrasound analysis 2 or 3 days before surgery. Subjects were examined in the sitting position with their forearm supinated. We prepared six wrist boards, each at a different angle from 0 to $75^{\circ}$ in $15^{\circ}$ increments. The wrist joint was secured onto the board and the resulting wrist joint angle was measured and adjusted by arthrometry (Fig. 1a).

Radial artery visualization was performed with a highresolution B-mode SonoSite ultrasonograph (iLook25, SonoSite, Bothell, WA, USA), which has a $5-10 \mathrm{MHz}$ broadband linear transducer and a probe with a calculated
Fig. 1 Ultrasound examination of the radial artery. a The wrist board and arthrometer used in the study. The wrist joint angulation was maintained at $45^{\circ}$ in this figure. b The sonography probe was placed over the point at which arterial pulsations were palpated most prominently. c, d Ultrasound images of the radial artery. The radial artery was visualized as a small, pulsatile, echolucent area. Vessel width was measured in (c), and vessel height was measured in (d)
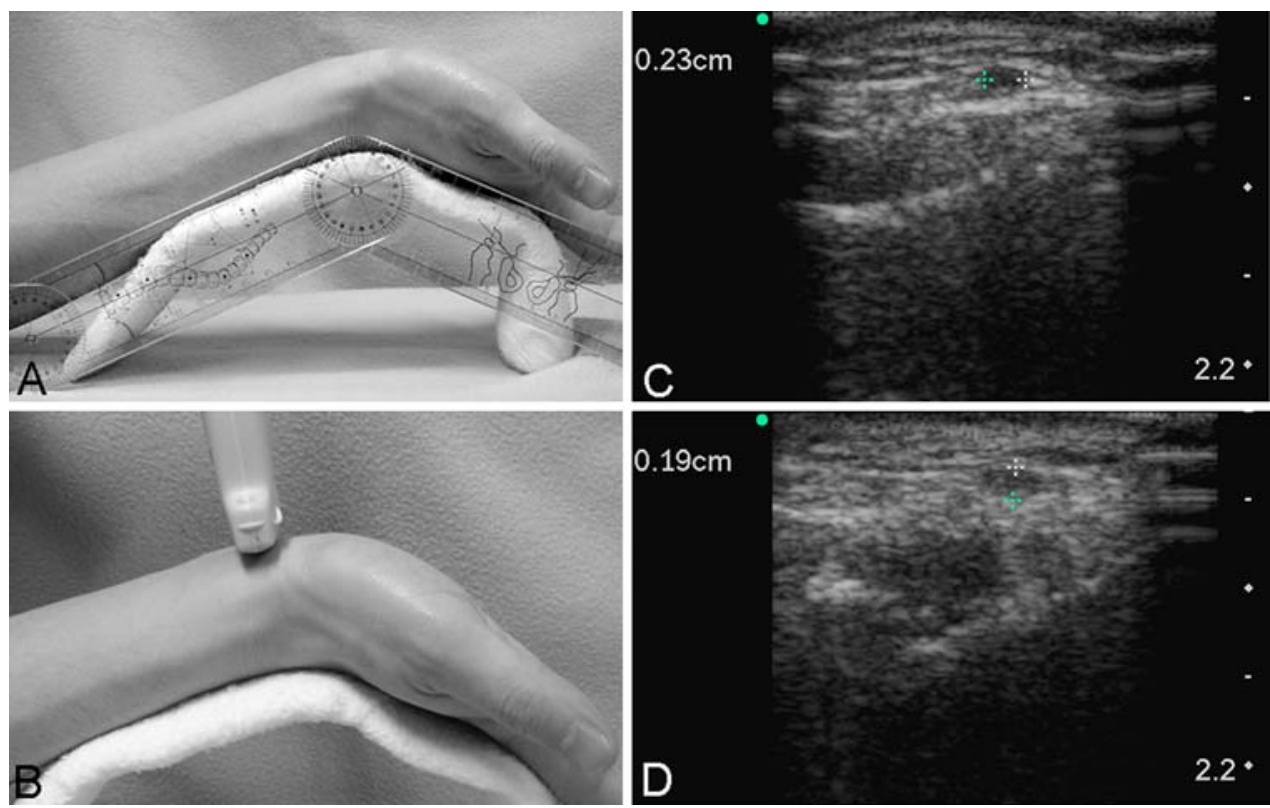
resolution of $0.15 \mathrm{~mm}$. The point where the arterial pulsations were most prominently felt was located by palpating around the styloid process of the radius at the wrist (Fig. 1b). Then, the probe was placed at that point, and the same probe position was maintained throughout the study. Arterial visualization was confirmed by observing pulsatile flow. Initially, the subjects' wrists were maintained level at a level angle of $0^{\circ}$, and transverse images of the radial artery were obtained. The subjects' wrists were then repositioned at progressively greater angles in increments of $15^{\circ}$ to a maximum of $75^{\circ}$, and transverse images were obtained at each increment. To minimize observer bias, we processed radial artery visualization according to the following procedure. First, we adjusted probe pressure so that the radial artery was not compressed by excessive pressure between the probe and the wrist joint. Next, we vertically adjusted the probe angle relative to the wrist joint to obtain a coronal image. Arterial images were taken only after the investigator confirmed that arterial deformity due to probe pressure and/or probe location had been eliminated. The above procedure was repeated throughout all measurements. Since arterial diameter can be affected by the phase of the cardiac cycle, the systolic phase of the cardiac cycle was determined by scrolling the digital images used for the measurements. One of the authors, who was blinded to the experimental conditions, measured the radial artery diameter from the acquired image. Anteriorposterior dimensions (vessel lumen height) and mediallateral dimensions (vessel lumen width) were measured by the leading edge to leading edge method (the distance between the proximal edges of the lumen-wall interface). Ultrasonic measurements were performed in both arms, each result being considered as a separate measurement. No statistical difference or relationship was observed between right and left radial artery size (data not shown).
To investigate baseline characteristics of radial artery size, we compared arterial dimensions among sub-groups (older patients $v s$ younger volunteers) and between genders.

As the study design was not a randomized controlled trial, we selected a convenience sample of 17 subjects for each group. To compare the resulting vessel dimensions at each set point of angulation within groups, repeated measures analysis of variance (ANOVA) was performed, followed by Tukey's test when ANOVA was significant. For the absolute changes of radial artery size, a one-sample $t$ test was performed to verify whether the data statistically deviated from $P=0.0$. Unpaired $t$ tests were used to investigate the effect of gender and subjects on baseline arterial size. Statistical calculations were performed with Prism (Graphpad Software Inc, San Diego, CA, USA) on a Windows XP computer. Data were shown as mean \pm SEM. Significance was assumed at $P<0.05$.

\section{Results}

All 34 subjects who were screened for this study agreed to participate. Complete measurements were obtained for all subjects. Figure 1c and d shows ultrasonic images of the radial artery at the level of the wrist joint. The radial artery was detected as a pulsatile vascular image. Figure 2 shows the distribution of vessel heights and widths of the radial artery with the wrist joint fixed at $0^{\circ}$. Vessel dimensions were significantly larger in males than in to females (Table 1) but did not differ between healthy subjects and CABG patients. The mean vessel width was $2.7 \pm 0.1 \mathrm{~mm}$ (ranging from 1.9 to $3.9 \mathrm{~mm}$ ) in healthy subjects and $2.9 \pm 0.1$ (ranging from 1.7 to $4.8 \mathrm{~mm}$ ) in patients undergoing $\mathrm{CABG}$. The mean vessel heights were $2.2 \pm 0.1 \mathrm{~mm}$ (ranging from 1.3 to $3.3 \mathrm{~mm}$ ) in healthy
Fig. 2 Radial artery diameter with the wrist joint in a neutral position. Vessel width was significantly greater than vessel height in both healthy subjects and $\mathrm{CABG}$ patients
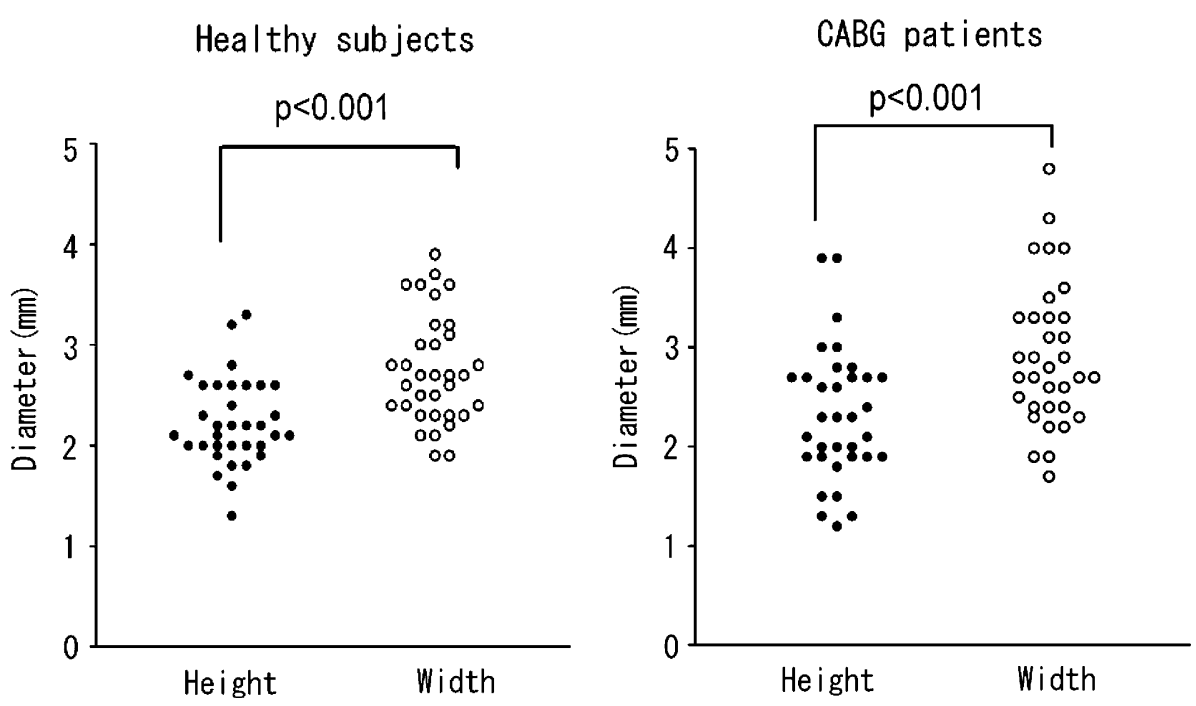
Table 1 Radial artery size in male and female subjects

\begin{tabular}{lll}
\hline & Male & Female \\
\hline Height $(\mathrm{mm})$ & $2.50 \pm 0.57^{* *}$ & $1.94 \pm 0.46$ \\
Width $(\mathrm{mm})$ & $3.01 \pm 0.63^{*}$ & $2.70 \pm 0.67$ \\
\hline
\end{tabular}

$* P<0.05 ; * * P<0.01$

subjects and $2.3 \pm 0.1 \mathrm{~mm}$ (ranging from 1.2 to $3.9 \mathrm{~mm}$ ) in patients undergoing $\mathrm{CABG}$. Vessel heights were smaller than vessel widths $(P<0.001)$. Changes to vessel height and width following wrist joint angle extension are shown in Fig. 3. ANOVA demonstrated that vessel height in healthy subjects decreased significantly when the wrist joint was extended to an angle of $60^{\circ}\left(P=0.027\right.$ vs $\left.0^{\circ}\right)$ and to an angle of $75^{\circ}\left(P<0.001\right.$ vs 0,15 , and $\left.45^{\circ}\right)$. Vessel heights in $\mathrm{CABG}$ patients showed a similar but more modest reduction when the wrist joint was extended to an angle of $75^{\circ}\left(P=0.008 v s 0^{\circ}\right.$ and $\left.P=0.015 v s 45^{\circ}\right)$. The average difference in vessel height between 0 and $75^{\circ}$ was $0.33 \pm 0.09 \mathrm{~mm}$ in healthy subjects and $0.20 \pm 0.08 \mathrm{~mm}$ in CABG patients (Table 2). Both sets of data showed statistical deviation from $P=0.0$ (one-sample $t$ test; $P=0.002$ for healthy subjects and $P=0.002$ for CABG patients). In contrast to vessel heights, vessel widths were unchanged in both groups, even when the wrist joint was extended to an angle of $75^{\circ}$ (Fig. 3, Table 2). No gender
Table 2 Mean difference in radial artery dimensions between 0 and $75^{\circ}$ wrist extension

\begin{tabular}{lll}
\hline & Healthy subjects & CABG patients \\
\hline Height $(\mathrm{mm})$ & $0.34 \pm 0.14^{* *}$ & $0.21 \pm 0.08^{* *}$ \\
Width $(\mathrm{mm})$ & $0.19 \pm 0.15$ & $0.03 \pm 0.09$ \\
\hline
\end{tabular}

** $P<0.01$

difference was found relative to the change of vessel dimension resulting from extending the angle of the wrist joint (data not shown).

\section{Discussion}

Although the generally recommended procedure for radial artery cannulation is to keep the wrist joint mildly dorsiflexed, ${ }^{8}$ the optimal wrist joint angle for arterial cannulation has not been established. Our results demonstrate that radial artery height decreases when the wrist joint is extended to an angle of $60^{\circ}$.

Radial artery dimensions measured with the wrist joint in a neutral position are consistent with previous investigations using ultrasound measurements. ${ }^{6}$ When the wrist joint was extended to an angle of $60^{\circ}$, vessel height decreased significantly. This likely occurred due to
Fig. 3 Effect of wrist joint angle on radial artery height and width. Vessel height (upper panels) and width (lower panels) are shown. Vessel height decreased as wrist joint angulation increased, while vessel width remained unchanged. Vessel height decreased in healthy subjects when the angle of the wrist joint was positioned at $60^{\circ}$ and in CABG patients when positioned at $75^{\circ} .{ }^{+} P=0.015$;

${ }^{++} P<0.001$ by Tukey's test
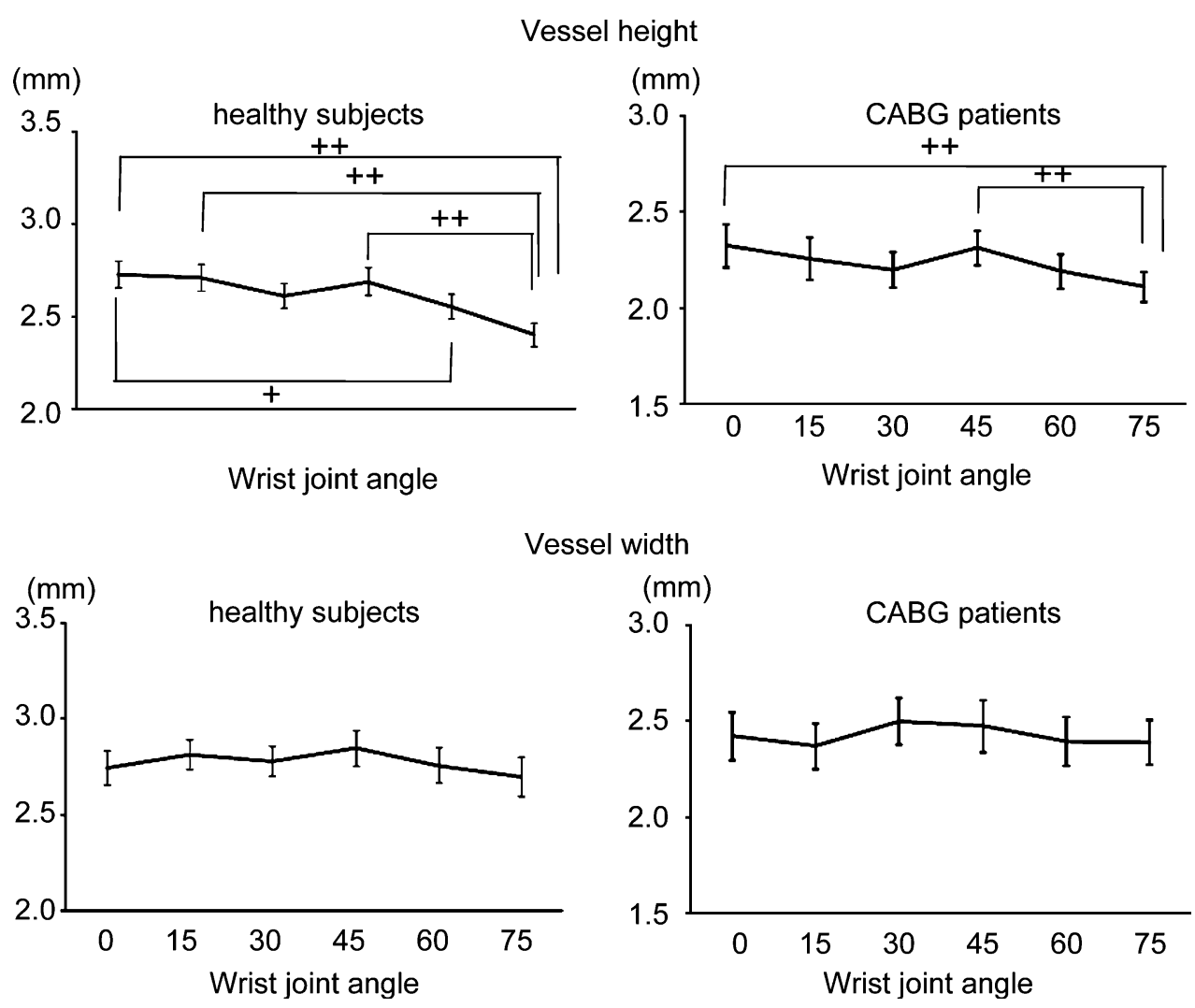

Vessel width

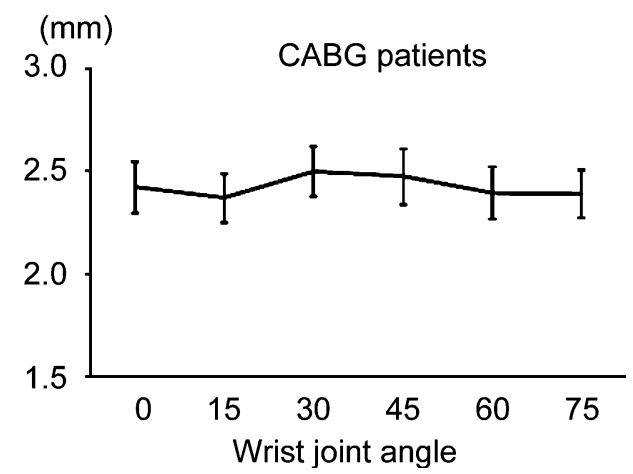


compression of the radial artery either by increased tissue pressure on the artery or by a reduction in vessel diameter due to stretching of the artery. The vessel height decreased most significantly at a $75^{\circ}$ angle. Changes in arterial dimensions due to wrist joint position were more modest in CABG patients. This might be due to different arterial characteristics between the two groups, i.e., CABG patients are more likely to have atherosclerotic-induced loss of arterial elasticity. Although different physical characteristics between the groups, including age and sex, may have influenced the results.

Our results show that the radial artery remains patent when the wrist joint is extended up to an angle of $45^{\circ}$. Considering the risk of median nerve compression by increased wrist extension, ${ }^{11}$ it may be safer during cannulation to maintain the wrist joint at a $15^{\circ}$ angle or less. Moreover, since radial artery occlusion during catheterization occurs more frequently with a smaller radial artery dimension, extending the angle of the wrist beyond $60^{\circ}$ may increase the risk of arterial occlusion and may be potentially harmful when the radial artery is catheterized.

Recent clinical studies have demonstrated that the success rate of radial artery catheterization is lower in females than in males. ${ }^{3,12}$ This result is likely due to the smaller size of the female radial artery. Our study focused on the relationship between the diameter of the radial artery and the angle of the wrist joint, and showed that excessive extension of the wrist joint angle reduces arterial size. There are no studies to show that the degree of wrist joint angulation influences the success rate of radial artery catheterization. Overextending the joint may reduce mobility of the vessels and increase the success rate of cannulation. The benefits of this position in terms of reducing the incidence of repeated attempts should be verified by further prospective studies.

We acknowledge several limitations related to this work. First, we measured radial artery dimensions at the site where arterial pulsations were most prominently felt. Although Sonocite ultrasonography is an established technique for peripheral vascular visualization, its resolution sensitivity may vary according to the radial artery dimensions, which potentially may have influenced our results. Further, probe pressure on the wrist or probe angle during questioning may have affected the measurements. Finally, this study was not designed to correlate radial artery dimensions with success rates of radial artery cannulation.
In conclusion, we evaluated radial artery diameter using ultrasound technology and found that a wrist joint angle of $60^{\circ}$ in healthy subjects and $75^{\circ}$ in CABG patients results in a decrease in the height of the radial artery, which could possibly render arterial catheterization more difficult. Disadvantages of wrist joint overextension during radial artery catheterization must be assessed in future clinical trials.

Conflicts of interest The authors declare no conflict of interest.

\section{References}

1. Scheer B, Perel A, Pfeiffer UJ. Clinical review: complications and risk factors of peripheral arterial catheters used for haemodynamic monitoring in anaesthesia and intensive care medicine. Crit Care 2002; 6: 199-204.

2. Karacalar $S$, Ture $H$, Baris $S$, et al. Ulnar artery versus radial artery approach for arterial cannulation: a prospective, comparative study. J Clin Anesth 2007; 19: 209-13.

3. Mangar D, Thrush DN, Connell GR, Downs JB. Direct or modified Seldinger guide wire-directed technique for arterial catheter insertion. Anesth Analg 1993; 76: 714-7.

4. Ludman PF, Stephens $N G$, Harcombe A, et al. Radial versus femoral approach for diagnostic coronary angiography in stable angina pectoris. Am J Cardiol 1997; 79: 1239-41.

5. Benit E, Missault L, Eeman T, et al. Brachial, radial, or femoral approach for elective Palmaz-Schatz stent implantation: a randomized comparison. Cathet Cardiovasc Diagn 1997; 41: 124-30.

6. Yokoyama N, Takeshita S, Ochiai M, et al. Anatomic variations of the radial artery in patients undergoing transradial coronary intervention. Catheter Cardiovasc Interv 2000; 49: 357-62.

7. Yoo BS, Yoon J, Ko JY, et al. Anatomical consideration of the radial artery for transradial coronary procedures: arterial diameter, branching anomaly and vessel tortuosity. Int J Cardiol 2005; 101: 421-7.

8. Mark JB, Slaughter TF. Cardiovascular monitoring. In: Miller RD, editor. Miller's Anesthesia. 6th ed. Philadelphia, PA: Churchill Livingstone; 2004. p. 1272-3.

9. Kiemeneij F, Laarman GJ, Odekerken D, Slagboom T, van der Wieken R. A randomized comparison of percutaneous transluminal coronary angioplasty by the radial, brachial and femoral approaches: the access study. J Am Coll Cardiol 1997; 29: 1269-75.

10. Kiemeneij F, Laarman GJ, de Melker E. Transradial artery coronary angioplasty. Am Heart J 1995; 129: 1-7.

11. Kuo MH, Leong CP, Cheng $Y F$, Chang $H W$. Static wrist position associated with least median nerve compression: sonographic evaluation. Am J Phys Med Rehabil 2001; 80: 256-60.

12. Ohara Y, Nakayama S, Furukawa H, Satoh Y, Suzuki H, Yanai H. Use of a wire-guided cannula for radial arterial cannulation. J Anesth 2007; 21: 83-5. 